\title{
Trends in death, disablement, and sickness absence in the British Post Office since 1891
}

\author{
P J TAYLOR* AND J BURRIDGE \\ From the Post Office Central Headquarters and Management Services and Sciences Department, British \\ Telecom, London
}

\begin{abstract}
The Post Office occupational health service was established in 1855. Unique epidemiological records of sickness absence, medical retirements, and deaths for 90 years have been extracted from annual reports. The stability of the death rate is striking, but the male sickness absence series is consistent with three periods of roughly constant rates, viz $7 \cdot 6,10 \cdot 0$, and $13 \cdot 1$ calendar days a year with increases in level coinciding with the two world wars. By contrast with general experience, Post Office absence has not shown a rising trend in the past 30 years. An examination of the relation between medical retirement and sickness absence rates shows that a strongly negative correlation has reversed to a strongly positive one since the second world war. The major changes in diagnostic causes of absence, retirements, and deaths are described.
\end{abstract}

The Post Office was legally established as a government monopoly in 1657 , but its main growth as a large employer came after Rowland Hill's introduction of the "Penny Post" throughout the country in 1840. Further expansions occurred after 1870 with the transfer of private telegraph companies to the Post Office, the opening of the first telephone exchange in 1879 , and the subsequent compulsory purchase of other private telephone companies in 1912. The newest function of the Post Office came with the formation of the National Girobank in 1968 , and by 1980 the whole organisation employed about 430000 people. After more than three centuries as a government department under the Postmaster General, the organisation, except for the department of National Savings, became an independent corporation (nationalised industry) in 1969. It is now (1981) to be divided into two separate corporations, Posts with National Girobank and British Telecom. The separation also affects the corporation's occupational health service, and this paper reviews the origins of the service and a unique 90-year series of reports on health and disease in the Post Office.

* Present address: Unilever Ltd, Unilever House, PO Box 68, London EC4P 4BQ

Received 30 April 1981

Accepted 29 May 1981

\section{Post Office medical service}

In 1854, during the last great cholera epidemic to affect London, the Postmaster General, Lord Canning, and the Secretary, Rowland Hill, decided that a doctor was required to advise and treat staff in London. This epidemic is remembered in medical history as the one in which Dr John Snow identified water from the Broad Street pump in Soho as a source of infection in that part of London. $\mathrm{Dr} \mathrm{H}$ Gavin, medical superintending inspector of the General Board of Health, was appointed on a temporary basis on 11 August at a daily salary of "three guineas and his cab hire."1 The urgency of the problem is illustrated by the fact that the Treasury agreed to this appointment only five days after Rowland Hill requested it. Dr Gavin's appointment ceased at the end of November, and Lord Canning wrote that he was highly satisfied with his work since "amongst the whole number (nearly 3000) under his charge only two deaths took place."

In January 1855 Lord Canning wrote again to the Treasury, drawing attention to a committee report on the organisation of the Post Office of May 1854 which had included a recommendation that all applicants for appointment should be medically examined "to ascertain that the candidate has no physical or medical defect or disease which is likely to incapacitate him for the public service." $\mathrm{He}$ 
requested that a medical officer be appointed, and he cited the presence of a doctor at the Custom House. The reply, which came in under three weeks, said that the Lords of the Treasury "entirely approved" but insisted that the post must be whole time. It had been the intention to appoint Dr Gavin, but he had died while inspecting military hospitals "in the East" so on 6 June 1855 Dr W A Lewis, a colleague of Dr Gavin's on the General Board of Health, was appointed for a salary of $£ 600$ a year. His duties were listed on 16 June 1855 as follows:

(1) to examine all candidates for appointment;

(2) to inquire into cases in which there is suspicion of feigned or exaggerated illness;

(3) to give advice and administer medicine at the General Post Office to all the officers of whatever grade who are attached to this office or to the money order office;

(4) to attend at their own homes such of these officers as belong to the class of letter carriers, stampers, porters, messengers, etc, and as reside within four miles of the General Post Office and who are unable to leave home;

(5) to examine from time to time into the sanitary conditions of the chief office and its branches;

(6) to examine applicants for pension with a view to its being ascertained whether the state of their health is such as to render their retirement necessary;

(7) to afford medical aid and in any other way the Postmaster General may think it right to direct; and

(8) the medical officer is debarred from private practice and is to give the whole of his time to the duties of his office.

The new medical service, which thus combined general practice with occupational health, was also set up in Liverpool, Edinburgh, Dublin, and then Glasgow by the appointment of part-time doctors in the same year. These doctors were paid $£ 25$ a year and a fee for each person examined; in Glasgow, for example, the fee was five shillings for a clerk and half-a-crown for a letter carrier. Further part-time appointments were made in 1858 in Manchester, Birmingham, Bristol, and Leeds, and in eight London districts the following year. These latter posts were paid by capitation fee (a system later adopted by the National Health Service) set at $8 / 6 \mathrm{~d}$ per employee a year, with medicines paid for separately. Dr Lewis was referred to as the Medical Officer in Chief, and his title was changed to Chief Medical Officer in 1873.

By 1870, 30 towns had Post Office doctors, and it was agreed by the Treasury that one could be appointed to any office employing at least 40 people. This was reduced to 20 people in 1876 , and the size limit was removed in 1903. Dr Lewis was provided with two full-time doctors to help him in 1873, a second medical officer and an assistant medical officer, and, after lengthy discussion, the Treasury agreed to the appointment of a woman medical officer in 1882. Dr Lewis died in September 1882 after 27 years' service and was succeeded by Dr G Steet, the second medical officer, whose duties had been mainly for the telegraphs department.

The service grew steadily over the next half century, and by 1936 there were 11 full-time doctors in London, including five women, and about 2600 part-time local medical officers elsewhere. ${ }^{2}$ Treatment was available free on a voluntary basis for staff earning under $£ 230$ a year in London or $£ 215$ in the provinces, the principle having been established in 1855 when the annual salary limit had been set at $£ 150$.

The advent of the National Health Service in July 1948 caused fundamental changes, since the entire population of the country became entitled to free treatment from a general practitioner. The Post Office Medical Service was abolished as a separate entity, and the doctors were transferred into the Treasury Medical Service, although they continued to work for the Post Office without providing treatment. ${ }^{3}$ The Chief Medical Officer became the Deputy Treasury Medical Adviser but continued as head of the Post Office Branch of the Treasury (later Civil Service Department) Medical Advisory Service. When the Post Office became an independent corporation outside the Civil Service in 1969, the service was reformed as an occupational health service. By the end of 1980, 26 full-time and over 40 part-time doctors as well as 78 occupational health nurses were employed, the first such trained nurse having been appointed in 1945 .

\section{Annual reports of the Chief Medical Officer}

Although Dr Lewis is known ${ }^{1}$ to have provided an annual report on his work for 1856 , in which he described having to reject $12 \%$ of candidates on the grounds of ill health, the earliest report still in existence is for 1891. It is clear from the way it is laid out that this was not the first one to include epidemiological information on sickness absence, medical retirements, deaths, and infectious diseases, as well as the results of pre-employment medical examinations. In 1860 all part-time local medical officers were required to provide annual returns of their work to Dr Lewis, so the series of reports probably began well before 1891. Most of the reports since that date are still available, although some are incomplete.

The reports are the more useful because the method of calculating sickness absence has been on a calendar day basis throughout, and, since the age of 
normal pensionable retirement was 60 years in 1891 , the rates for premature medical retirement have always been calculated for staff under this age. The reports before world war I contained sections on "zymotic diseases," which listed cases of infectious or contagious disease, and until 1957 there were also detailed descriptions of the incidence of and mortality from tuberculosis. Apart from the basic tabulations that remained substantially unchanged, the reports varied in the amount of comment and opinion. Some were little more than tables with brief explanatory notes; others, like those by Dr Wilson at the end of the nineteenth century, Sir Henry Bashford from 1934 to 1943, and Dr Cecil Roberts from 1946 to 1952 , included a great deal of interesting comment.

\section{ANNUAL REPORT FOR 1891}

The Annual Report for 1891 was submitted to the Secretary by Dr Arthur Wilson in June 1892. He had just succeeded Dr Steet, who had retired at the end of 1891, and this was therefore his first report. Most of its 33 pages were devoted to sickness absence, and figures were included for all offices throughout Great Britain and Ireland. The overall sick rate (average annual duration per person) was 8.9 calendar days among the 43187 men and 15.7 days among the 4077 women. For comparison, the figures for 1979-80 were $12 \cdot 3$ days for men and 15.9 days for women. By contrast with recent experience, the male sick rate in London ( 9.8 days) was higher than that in the provinces and in Ireland, while Scotland had the lowest rate of 8.2 days. As one might expect, mean sick rates in individual offices varied widely; the 20 men and two women employed at Henley-on-Thames, for example, had no sick leave at all, but the 29 men at Worthing in Sussex recorded a mean rate of 26.5 days. Among large offices, Dublin with 1047 men recorded a mean rate of 17.9 days, and this resulted in a special visit by Dr Wilson in 1892 .

The report contained much outspoken critical comment about a change in sick pay arrangements introduced in 1890 . Hitherto staff had received twothirds pay for the first six months of sick leave followed by half pay for a further six months. In April 1890 the first six months rate was raised to full pay except for absences lasting under one week for which the two-thirds rate still applied. Dr Wilson wrote, "... the present system will be continually abused, and I therefore strongly urge that full pay, with no restrictions, should be allowed in every case of certified bona fide sickness." His advice was ultimately accepted, and full pay was awarded for all absences up to six months in 1894. Later in the report he described a problem faced by Post Office doctors that can still cause difficulties for occupation- al physicians. The free provision of treatment and certificates by Post Office doctors was voluntary for staff; others, and those living too far from their offices, were free to consult any doctor they wished. Certificates from other doctors, which apparently cost 6d, were countersigned by Post Office doctors before sick pay was given. Dr Wilson wrote: "From my own experience I know the difficulties, unpleasantness, responsibilities that arise from too rigidly watching sick-absentees and the consequent odium the medical officer incurs with the patient who invariably afterwards seeks the advice of outside doctors ... it also lays the medical officer open to the charge that professional etiquette has been outraged if the certificates of neighbouring practitioners are even questioned."

The list of causes of deaths in service in 1891 provides an interesting contrast with present day experience. Only 24 of the 232 deaths of men were attributed to heart disease and only five to cancer, proportions of $10 \%$ and $2 \%$ compared with $44 \%$ and $32 \%$ respectively of the 1164 deaths in men in 197980 . On the other hand, there were 70 deaths from tuberculosis, 10 from influenza, five from typhoid, and two from typhus, none of which caused death in 1980. Two were recorded as due to alcoholism, a proportion similar to that in 1979-80 when there were ten. Deaths were classified in three main groups: "miasmatic," which included most infectious disease; "dietic," which included alcohol; "constitutional," which included cancer, phthisis, scrofula, and diabetes; and "local" including heart, digestive, and other bodily system diseases. There were seven deaths from violence.

The complement of doctors in 1891 was five fulltime doctors in head office and 349 part-time doctors at other offices. Extracts from 11 of the reports from part-time doctors were added to the report to strengthen the criticism of the new sick pay scheme. One of the most forcefully worded was by Dr Fitzwillion in Dublin who wrote: "The existing rule is felt to be a great injustice by the honest men who forfeit a third of their pay if they resume duty after a few days' illness, while it is a direct premium to the dishonest to insist on their inability to resume under a week and it brings the medical officer into an unpleasant friction with those under his care."

The appendices giving details of zymotic diseases and medical retirements are missing, but the report for 1892 describes two mild cases of smallpox, while five occurred in 1893. Dr Wilson commented that the mild nature of the illness could be attributed only to the rule that every new employee was required to provide proof of satisfactory vaccination. Causes of medical retirement appear in the 1893 report and show that of 191 men, the commonest causes were 
tuberculosis ( 32 men), chronic rheumatism (27); and 10 each ascribed to heart disease and "paralysis." The prominent place of musculoskeletal conditions still holds good today, and they caused $23 \%$ of 1651 medical retirements in men in 1979-80; there were only four due to tuberculosis.

Dr Wilson retired in 1900 and his successors Dr Sinclair and Dr Prynne wrote less discursive annual reports, but after the appointment of Dr Bashford in 1933 more informative comment was reintroduced; perhaps the most interesting series was written by Dr Roberts, who was Chief Medical Officer at the time when the old Post Office Medical Service was disbanded.

ANNUAL REPORT FOR 1949

The Annual Report for 1949 is of particular interest since it describes the first full year after the start of the National Health Service in July 1948, and the almost coincidental start of universal National Insurance with tax free sickness benefit for all employed persons. Dr Roberts noted that the mean sick rate had risen to exceptionally high levels, and although this might in part be explained by an outbreak of influenza, the main reason was in his view the loss of the direct influence previously provided by the medical service. He explained how the system had changed: "By long established practice, certificates from officers not using the Post Office doctor were countersigned by the Post Office doctor whose concurrence in the necessity for the sick absence was a condition of sick pay. In recent years this control was exercised most humanely, stoppage of sick pay being an extreme rarity, and although various restrictions remained in the rule books they were hardly ever exercised. Nevertheless, the authority and means to supervise sick absence were there and undoubtedly exercised a restraining influence, not strong enough to cause people to work when they were unfit but enough to make the weak vessel watch his or her step. Under the changed circumstances of today, the Post Office is not at present any longer in a position to exert effectively this restraining influence." He went on to note that the rules for National Insurance certificates encouraged absences to last for multiples of a week and that whereas previously employees could usually see the Post Office doctor at work, they now took a day off to see their own general practitioner. The financial situation of those off sick had also changed; before July 1948 they had received the same pay when off sick, since then they received more, because the weekly National Insurance contribution was not deducted and, further, that element of sick pay which was due to them as state sickness benefit was tax free. $\mathrm{He}$ ended by remarking: "It needs a strong will and great honesty of purpose to return to work as soon as possible after illness if money is lost by doing so."

Elsewhere in the report he noted that the incidence of pulmonary tuberculosis at $1 \cdot 19$ per thousand staff was falling satisfactorily; this rate was derived from 427 cases notified in the year, and the number of deaths and medical retirements from the disease amounted to 31 and 35 respectively. Malignant disease had become a great deal more important than it had been in 1891 and accounted for $28 \%$ of deaths and $4 \%$ of retirements in men, while heart disease too had increased considerably to account for $25 \%$ of male deaths and $13 \%$ of retirements.

\section{Sick pay and uncertificated sick leave arrangements}

Until the middle of the nineteenth century there was no formal sick pay, but local arrangements gradually developed allowing an officer on sick leave to receive a temporary pension until he was fit to return to work. The Treasury disapproved and suggested in 1857 that full pay would be more appropriate for the first six months and half pay for the second six months in any four-year period. The Postmaster General refused to introduce a general scheme since he feared that it "might induce officers to malinger." Nevertheless, local, and thus unofficial, sick pay schemes usually including half pay became more common. When, in 1870, the telegraphists employed in private companies were transferred to the Post Office, they retained their previous rights to two-thirds pay for six months' sick leave. This was quickly extended, against the Postmaster General's wishes, to other staff in large cities, and in 1872 a minimum rate of half pay for one year was decreed throughout the Post Office, although two-thirds pay for the first six months rapidly became general. In 1890 full pay was approved for the first six months except for absences of under one week for which two-thirds pay only was to be given. The consequences have already been described, and by 1894 full pay was officially allowed for the first six months in all cases followed by half pay for the second six months, sick pay to cease after 12 months in any 18-month period. This arrangement has continued to the present day, but since 1948 the half pay has been exclusive of any National Insurance Sickness Benefit to which the sick person is entitled.

The Post Office, in common with the Civil Service and HM Forces, operates an arrangement with the National Insurance Fund whereby employees agree not to claim individual sickness benefit during the first six months of sick leave but receive full pay, which includes a tax free element from the National Insurance Fund each year and in 1979-80 it amounted to $£ 12.6 \mathrm{~m}$. This permits the Post Office much greater 
flexibility in the matter of uncertificated sick leave than has been possible for other employers who have been restricted by the National Insurance certification rules.

Sick leave accepted without a medical certificate was first mentioned in a document of 1870 as being permissible for single day absences. In 1890 an official arrangement, applicable only to more senior clerks, was introduced, which allowed them to take uncertificated absences for up to two days at a time and to a maximum of seven days in one year. Informally, however, this arrangement was soon extended to lower grades. Dr Wilson's report for 1892 described: "a privilege extended to staff in many offices, viz that of being self-excused duty for one or two days on sick notes." He observed that the frequency of sickness absence lasting up to five days was much higher in those offices. It is not clear when the official rules for senior clerks were extended to all employees. The two-day maximum duration was extended to four as a wartime arrangement in 1943 and further extended to a maximum of five working days in one spell in 1966 when the annual total permitted was raised from seven to ten days. The arrangement, which is officially termed a "privilege" and may be withdrawn from any who can be shown to have abused it, has since remained unchanged.

Routine analyses of uncertificated sick leave only began in 1960, when more detailed information became available from the sampling system, and $80 \%$ of all such spells were found to be for one day only. When fuller analyses were made for 1966-7 these spells accounted for $64 \%$ of all absences in men and $66 \%$ in women, but in terms of total days of absence, uncertificated sick leave accounted, in men, for $12.5 \%$ of total days (14.9\% for women). In the past ten years this type of absence has been more extensively studied. In $1979-80$, for example, $37 \%$ of staff took no uncertificated absence at all, $45 \%$ took only one to three days, and only $1 \%$ took over seven days. Apart from a small handful of individuals from whom the privilege may be withdrawn each year, there is no evidence of significant abuse, and the allegations that Post Office staff (and civil servants) all take their full entitlement of uncertificated sick leave is inaccurate.

\section{Employment of disabled}

Sickness absence data were presented separately for disabled and non-disabled men for every year from the end of the first world war until 1959. The two categories of men were kept separate because the Post Office employed a large number of war disabled (King's Roll) men as a matter of policy. These arrangements gave priority to war disabled men for any established post that it was thought they could undertake and even in 1919 there were already 16505 such men $(9.5 \%$ of the total staff). The numbers and percentages rose until 1932 when 28589 disabled men were employed $(14.4 \%$ of the total staff) and their sick rate was 13.6 days per man compared with 10.5 days for non-disabled established men. Even in 1946, when recruitment under the new Disabled Persons Employment Act of 1944 had started, there were still 17730 disabled men (most of whom were first world war disabled) amounting to $8.7 \%$ of the total staff.

The Post Office was thus well prepared for the "quota" introduced by the 1944 Act. This was initially set at $2 \%$ in March 1946, but it was soon raised to $3 \%$ at which it remains today. The Post Office set as its formal policy that registered persons should be recruited to any established post provided that they were found to be "not less than $75 \%$ efficient" compared with a normal employee in that grade. This criterion is usually difficult to measure, but the concept has been valuable. The largest number of registered disabled persons (22 064) was employed in 1950 when they amounted to $7.9 \%$ of the total staff. The annual percentages have fallen ever since, $4 \%$ in $1959,2.5 \%$ in $1968,2.0 \%$ in 1975 , and $1.5 \%$ in 1980 ; this has mainly been due to the steadily falling numbers of people registered under the Act, ${ }^{5}$ and partly because the Post Office now employs twice as many people as it did in 1946. Interna! surveys have shown that under half the people employed who are known to be disabled are registered under the Act; and this confirms results of studies in other organisations. ${ }^{6}$

\section{Time trends in absence, retirements, and deaths}

Annual rates of sickness absence, medical retirements, and deaths in service from 1891 to 1980 are shown in fig 1 for men and in fig 2 for women.* Sickness absence rates were not calculated for the war years 1917-18 and 1939-45 (wartime rates excluded staff on active service) while records of medical retirements and deaths for 1906 and 1912 cannot be traced, nor can the retirement rates for women for 1894-8. With these few exceptions the data provide a series unique in occupational health publications. The sampling system from which more detailed information about sickness absence was obtained was introduced with the assistance of Professor D D Reid in 1960.

Two features of the trends (figs 1 and 2) are most striking. Firstly, the long-term stability of the male and female death rates with the main exception of

*The raw data from which these figures have been constructed are available on request from PJT. 


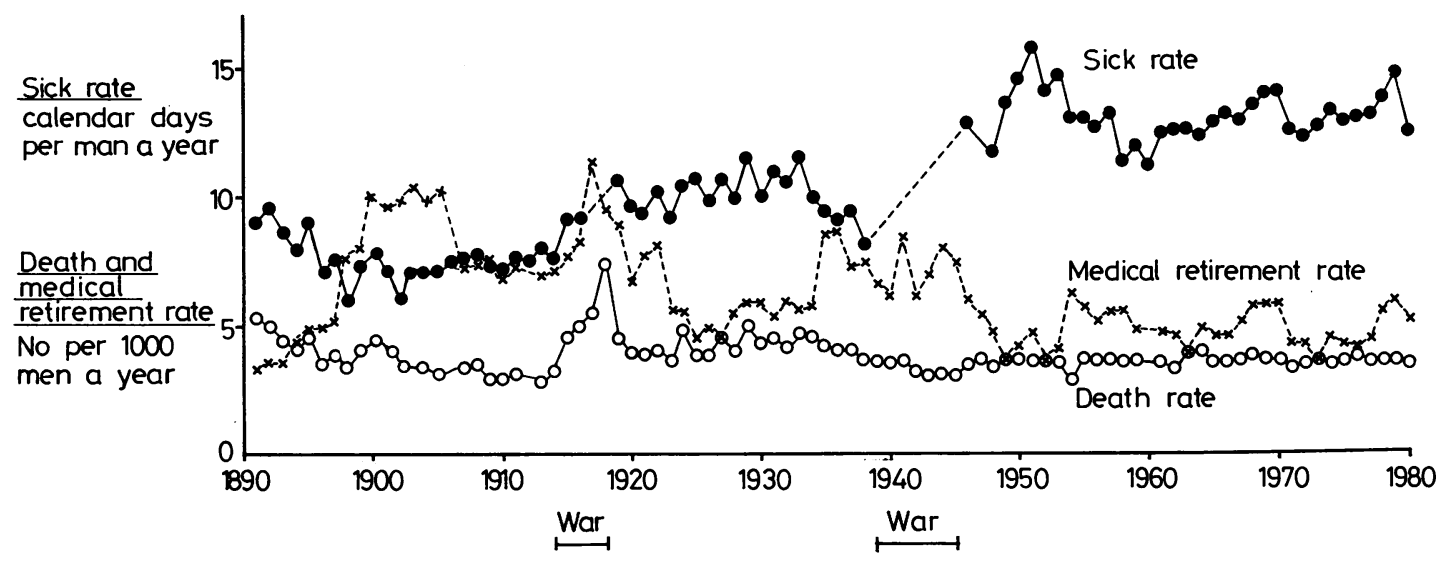

Fig 1 Men in Post Office 1891-1980. Sick rate, death rate, and medical retirement rate.

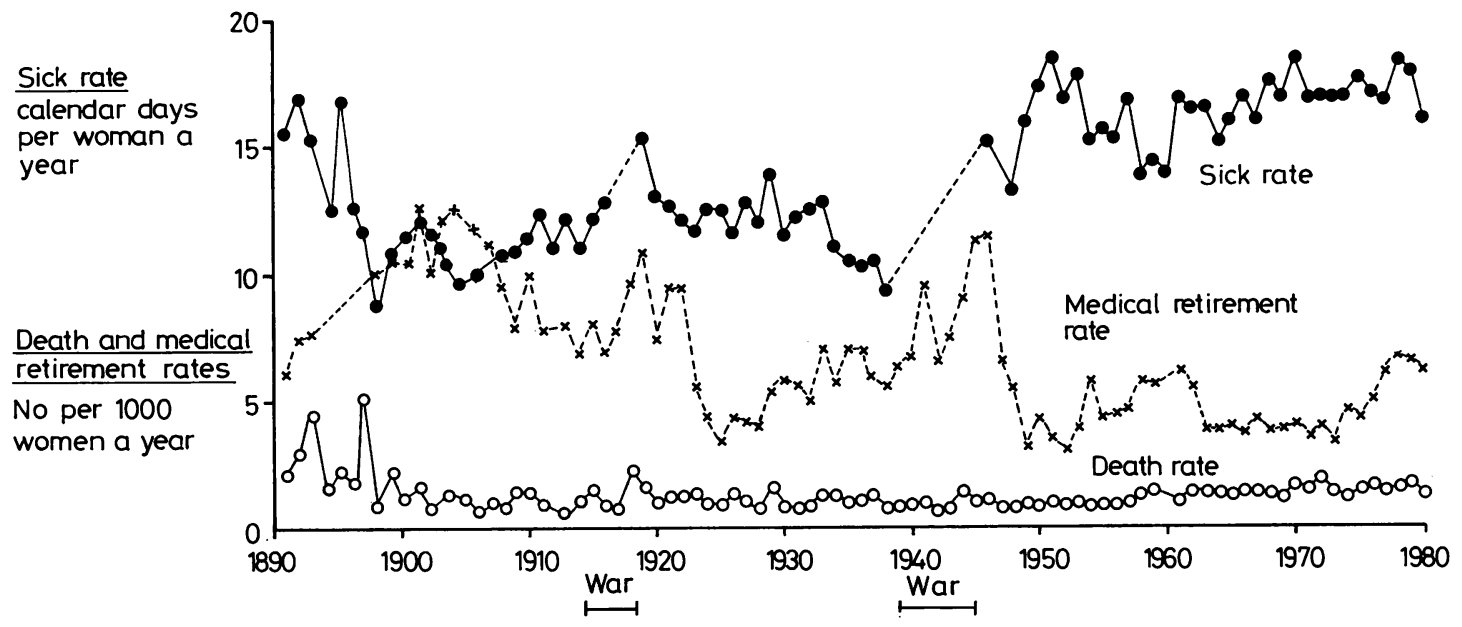

Fig 2 Women in Post Office 1891-1980. Sick rate, death rate, and medical retirement rate.

1918 , the year of the great "Spanish" influenza pandemic. This long-term stability is the more striking in view of the major changes in the pattern of disease indicated by the causes of death described from the 1891 report, and from a more recent comparison over 20 years described later. The variations in the early female death rates (1891-1900) may be attributed largely to the relatively small number at risk. Effects of population-age structure will be considered below.

The second feature of note is the long-term increase in sickness absence rates. While similar patterns are shown in both men and women, at least some of those in women are influenced by appreciable changes in age structure. The Post Office operated a "marriage bar" for women (forbidding the employment of married women) until 1948, and although detailed age distributions are not known for every year until 1960, data are available for two of the earlier years, 1923 and $1934 .{ }^{7}$ Age standardisation of sickness absence rates to the 1979-80 populations of men and women for the years 1923 and 1934 and for each year since 1960 show that for men the differences from observed sick rates would be under 0.5 day for the first two of these years and within the limits of rounding errors of 0.1 day since 1960. In the female population, however, the age standardised rates for 1923 and 1934 would be about two days higher than observed, due to the smaller proportion of older women employed before the war. Between 1960 and 1968 age standardisation would have raised female rates by between 0.2 and 0.4 days, but since then the age structure has had no effect. These findings suggest that the observed 
male series can be used for examining long-term trends.

The two world wars form natural breaks in the sickness absence series both in terms of the completeness of records and also of the fundamental political, social, and economic changes that took place in British society. For these reasons it seemed reasonable to consider whether the long-term rise is compatible with a single linear trend or, alternatively, whether it is better explained by three separate trends corresponding to the periods 18911913, 1919-38, and 1946-80. These two hypotheses were compared using a standard F-test. ${ }^{8}$ For the first hypothesis of a single linear trend $F=16.56$ $(p<<0.01)$ on 4 and 71 degrees of freedom; this provides strong evidence against the single linear trend hypothesis. A similar test of whether the overall trend is consistent with three different constant levels or three separate trends gave $F=1.41(p>0.05)$ on 3 and 71 degrees of freedom; this shows that there is no evidence against three constant levels, apart from the obvious shortterm fluctuations.

The period 1949-53 was exceptional, and its origins have already been described in the section on the 1949 Annual Report. The peak rate was reached in both sexes in 1951, and the reduction in sick rate that followed was associated with a general tightening up of managerial control of absence using pre-existing procedures that had not been widely applied in earlier years. There seems no reason to doubt the views of CMOs and others expressed at the time-namely, that the abolition of the old style Post Office Medical Service and the coincidental introduction of National Insurance sickness benefit for all, together with an influenza epidemic in 1951 were the main reasons for these few years of exceptionally high sick rates.

In view of these results it seems reasonable to conclude that male sickness absence rates have been consistent with three distinct periods of roughly constant rates separated by the world wars. These levels were $7 \cdot 6 \pm 0 \cdot 2$ days before $1914,10 \cdot 0 \pm 0 \cdot 2$ days between the wars, and $13 \cdot 1 \pm 0 \cdot 2$ days since

Table 1 Postmen's sick rates in selected cities and towns*

\begin{tabular}{lrrrrrrr}
\hline Town & $\begin{array}{c}\text { Mean } \\
1936-8\end{array}$ & 1940 & 1941 & 1942 & 1943 & 1944 & 1945 \\
\hline London HQ & $8 \cdot 2$ & $10 \cdot 3$ & $9 \cdot 1$ & $10 \cdot 5$ & $12 \cdot 4$ & $12 \cdot 8$ & $15 \cdot 7$ \\
Birmingham & $11 \cdot 0$ & $11 \cdot 6$ & $10 \cdot 1$ & $12 \cdot 0$ & $16 \cdot 7$ & $17 \cdot 9$ & $17 \cdot 9$ \\
Manchester & $11 \cdot 0$ & $14 \cdot 4$ & $13 \cdot 5$ & $13 \cdot 9$ & $15 \cdot 7$ & $17 \cdot 4$ & $20 \cdot 9$ \\
Liverpool & $9 \cdot 9$ & 12.4 & $15 \cdot 5$ & $16 \cdot 4$ & $19 \cdot 5$ & $19 \cdot 3$ & $19 \cdot 2$ \\
Bristol & $11 \cdot 3$ & 16.5 & $15 \cdot 7$ & $13 \cdot 6$ & $18 \cdot 1$ & $21 \cdot 9$ & $18 \cdot 4$ \\
Glasgow & $9 \cdot 8$ & $11 \cdot 6$ & $12 \cdot 3$ & $14 \cdot 7$ & $17 \cdot 1$ & $19 \cdot 4$ & $17 \cdot 4$ \\
Belfast & $10 \cdot 2$ & $7 \cdot 5$ & $9 \cdot 6$ & $13 \cdot 7$ & $15 \cdot 2$ & $11 \cdot 7$ & 16.6 \\
\hline
\end{tabular}

*From CMO's Annual Report for 1945.
1945. Although there are no national Post Office data for the war years, the CMOs Annual Report for 1945 did include figures for postmen from some of the larger offices throughout the war (table 1). All showed substantial increases and the rates rose in each year from 1940 to 1945. Sir Henry Bashford had already published his views on the effects of war on Post Office sickness absence, ${ }^{9}$ and attributed the rise in rate to problems such as the bombing, long hours of firewatching, and the extra work due to the shortage of staff. Had these been the only problems one might have expected rates to have fallen to prewar levels when hostilities ceased, but they did not. Perhaps both world wars produced long-lasting changes of attitude toward absence from work due to incapacity among staff, not only in the Post Office but in all probability throughout society.

Apart from these major changes in absence rate, relatively short-term trends have been superimposed, such as the 1949-53 period already discussed, and there was also a substantial fall in the rates from 1933 to 1938. Epidemics of influenza too have had their effects on single years such as 1957 (Asian flu) and 1969-70 (Hong Kong flu). This and other aspects of short-term trends require further analysis and will be explored in a future paper together with other socioeconomic indices, such as levels of unemployment and the business cycle.

The medical retirement rate series and its relationship to sickness absence is also worth comment. The rates throughout the period have been for staff aged under 60 , and the official criteria for medical retirement have not changed. These are that the individual shall be certified by a Post Office doctor as being unfit to render regular and effective service in the duties of his or her grade, thus it is not necessary for the person to be totally unfit for any sort of work. Alternative work within the Post Office is always considered before medical retirement can take effect, but for various reasons this is difficult to arrange for more than a small proportion. There is scope for some variation in attitudes between managers and furthermore those of the individuals themselves also influence the outcome, and these aspects have been discussed in reports from the Post Office. ${ }^{10-12}$

The relationship between sick rate and medical retirement rate was postulated by Roberts $^{3}$ as a clear-cut negative correlation, in that more strict enforcement of medical retirement policy resulted in lowered sickness absence rates. Inspection of fig 1 suggests that this may have been the case in the first half of the series, but recent experience has been rather different. Calculation of a correlation coefficient for the whole series gives $r=-0.598(p<0.001)$ or $r=-0.505(p<0.001)$ after allowing for trend. This strongly supports the Roberts hypothesis. If 
the more stable report period between 1954-80 is considered the correlation reverses and becomes $r=+0.434(\mathrm{p}<0.05)$ or $\mathrm{r}=+0.586(\mathrm{p}<0.01)$ after allowing for trend. A possible explanation for these apparently contradictory results is that two different processes are taking place: periods of negative correlation correspond to periods of transition from less to more strict application of medical retirement criteria (and vice versa), whereas the more recent period of about 25 years, when positive correlation applies, has been a relatively stable time during which annual variations in the health of staff have lead to corresponding changes in both sickness absence and medical retirement rates. A more careful study of such phenomena would need to examine the behaviour of the sickness absence distribution in addition to the overall rates.

\section{Age-specific sick rates}

No routine records of the age structure of Post Office staff were kept until 1960, and annual details of age and diagnoses of absence are only available since then. Fortunately a special inquiry into Post Office sick rates had been made by the Government Actuary at the request of the Postmaster General, and the report ${ }^{7}$ includes details of absence by age for the three triennia 1923-5, 1929-31, and 1932-4. The age-specific sickness absence rates for the first and third of these periods are set out with rates for the pairs of years 1960-2 and 1978-80 in figs 3 and 4. The actuary's tables did not include staff over 60 but clearly the higher overall rates in the later years were due to substantial increases in sick rates among younger employees. Indeed those of women aged 50-59 showed no change in over half a century. No direct statistical tests of sick rates have been made since the well-recognised extreme skewness of

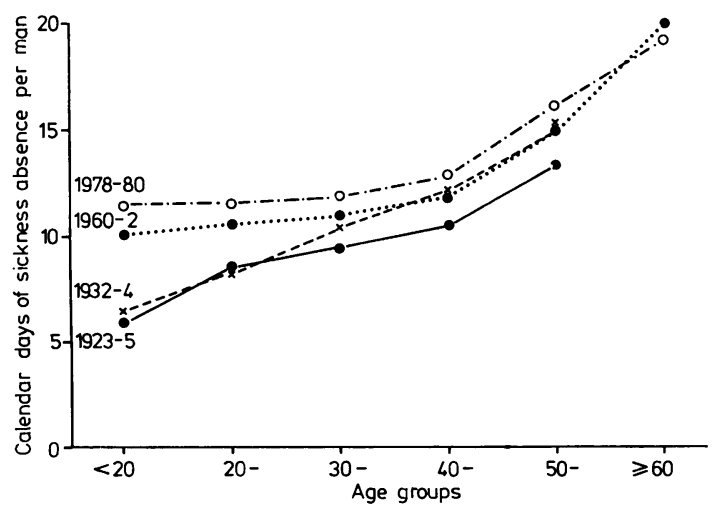

Fig 3 Sick rates in Post Office men by age 1923-5, 1932-4, 1960-2, and 1978-80.

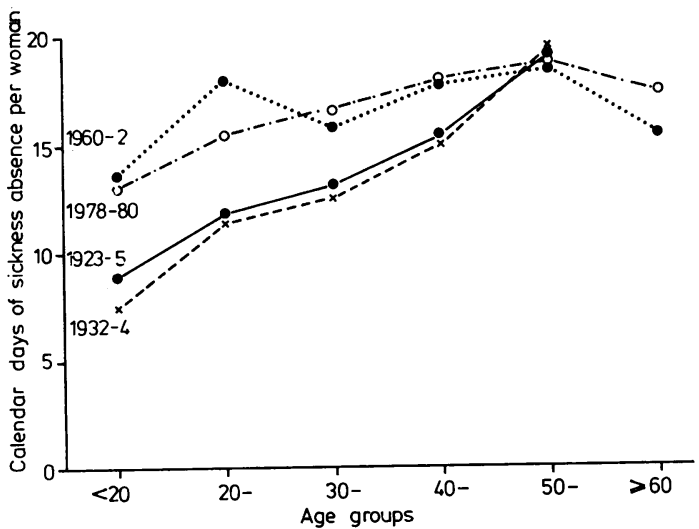

Fig 4 Sick rates in Post Office women by age 1923-5, 1932-4, 1960-2, and 1978-80.

absence frequency distributions makes tests with untransformed variates unreliable, and the consistency and the magnitude of the differences make more elaborate tests unnecessary.

\section{Changing patterns of disease}

The contrast between causes of death and medical retirement in the 1890s and the present day have already been described. The diagnoses of sickness absence have only been collected as a routine since 1960. The main diagnostic groups causing sickness absence in 1960-2 are set out in table 2 together with those for 1978-80. Although the overall rate for men rose by only $9 \%$ and that for women by a negligible $1 \%$, the diagnostic pattern changed substantially. As has been described, the age structure of the populations over this 20-year period did not alter to any significant extent, and thus the alterations in diagnostic sick rates are not a consequence of any change in age structure. Absence due to diseases of

Table 2 Changes in main diagnoses of sickness absence in Post Office staff 1960-2 to 1978-80. (Rates in calendar days per person)

\begin{tabular}{|c|c|c|c|c|c|c|}
\hline \multirow[t]{2}{*}{ Diagnostic group } & \multicolumn{3}{|l|}{ Men } & \multicolumn{3}{|c|}{ Women } \\
\hline & $\begin{array}{l}\text { Mean } \\
\text { rate } \\
60-2\end{array}$ & $\begin{array}{l}\text { Mean } \\
\text { rate } \\
78-80\end{array}$ & $\begin{array}{l}\text { Change } \\
\%\end{array}$ & $\begin{array}{l}\text { Mean } \\
\text { rate } \\
60-2\end{array}$ & $\begin{array}{l}\text { Mean } \\
\text { rate } \\
78-80\end{array}$ & $\begin{array}{l}\text { Change } \\
\%\end{array}$ \\
\hline \multicolumn{5}{|l|}{ Coronary heart } & $0 \cdot 17$ & +325 \\
\hline Musculoskeletal & $1 \cdot 08$ & $2 \cdot 03$ & +88 & 0.98 & $1 \cdot 89$ & +93 \\
\hline Psychiatric & $0 \cdot 29$ & 0.54 & +86 & 0.80 & $1 \cdot 26$ & +58 \\
\hline Injuries & $1 \cdot 24$ & $2 \cdot 11$ & -+70 & $0 \cdot 78$ & $1 \cdot 66$ & +113 \\
\hline Other cardiovascular & $0 \cdot 52$ & 0.64 & +23 & 0.47 & 0.66 & +40 \\
\hline Tumours & 0.05 & 0.06 & +20 & 0.09 & $0 \cdot 14$ & +55 \\
\hline Gastrointestinal & $1 \cdot 74$ & $1 \cdot 21$ & -31 & 1.90 & $1 \cdot 25$ & -34 \\
\hline Respiratory & $4 \cdot 90$ & $3 \cdot 19$ & -35 & $6 \cdot 52$ & $4 \cdot 21$ & -35 \\
\hline Other causes & $2 \cdot 39$ & $3 \cdot 29$ & $-+38 \ldots$ & $5 \cdot 20$ & $5 \cdot 71$ & +10 \\
\hline All causes & $12 \cdot 45$ & $13 \cdot 58$ & +9 & $16 \cdot 80$ & $16 \cdot 95$ & +1 \\
\hline
\end{tabular}


the respiratory and gastrointestinal systems fell by about one-third, but there were substantial rises in rates due to coronary heart disease, musculoskeletal conditions, and psychological disorders. Simple statistical tests are not appropriate for sickness rates, but these changes in diagnostic pattern are supported by more objective evidence from deaths and medical retirements.

Although routine annual analyses of the diagnostic causes of death and retirement by age and by job started only in 1972, it is fortunate that the results of a large-scale "ad hoc" study for the ten years 1953-62 have been found in the files. This covered all staff between 25 and 59 in six of the largest male and three large female job groups; the man-year populations at risk were over 1.6 million men and some 240000 women. These data have enabled age standardised comparisons to be made for staff of the same age range and in the same jobs for 1978-80. Observed and expected numbers of deaths and medical retirements for the main diagnostic groups are set out in tables
3 and 4 . The expected numbers were derived from age-specific rates in the earlier period applied to the populations at risk 1978-80. As with sickness absence rates, the overall rates for men and women changed little, but there were major changes in causes. The largest rises occurred in musculoskeletal conditions and in coronary heart disease. For people in employment, death in service or medical retirement are often alternative outcomes with clinically similar conditions, and thus the combination of both, termed "medical wastage," is a more appropriate measure. ${ }^{10}$ Standardised wastage ratios are therefore included in tables 3 and 4 . The increases in some diagnostic groups have been matched by reductions in others, of which tuberculosis was the most dramatic. The low incidence of this disease in Post Office staff in the 1970s has already been described. ${ }^{13}$ Substantial reductions in wastage from gastrointestinal, genitourinary, and the group of central nervous and special sensory system disorders, were also recorded. Respiratory disease,

Table 3 Twenty-year changes in causes of medical wastage in men aged 25-59. (Men dying or medically retired in 1978-80 compared with expected number had age-specific rates for 1953-62 applied to 1978-80 populations)

\begin{tabular}{|c|c|c|c|c|c|c|c|}
\hline \multirow[t]{2}{*}{ Diagnostic group } & \multicolumn{2}{|c|}{ Deaths } & \multicolumn{2}{|c|}{ Medical retirements } & \multicolumn{2}{|c|}{ Wastage } & \multirow[t]{2}{*}{ Standard wastage ratio } \\
\hline & Obs & Exp & Obs & Exp & Obs & Exp & \\
\hline Musculoskeletal & 5 & $0 \cdot 8$ & 701 & $367 \cdot 3$ & 706 & $368 \cdot 1$ & $192 \ddagger$ \\
\hline Coronary heart disease & 554 & $420 \cdot 3$ & 379 & $236 \cdot 6$ & 933 & $656 \cdot 9$ & $142 \ddagger$ \\
\hline Injuries & 68 & $60 \cdot 0$ & 55 & $47 \cdot 8$ & 123 & $108 \cdot 0$ & 114 \\
\hline Other cardiovascular & 132 & $269 \cdot 2$ & 272 & $97 \cdot 7$ & 404 & 366.9 & 110 \\
\hline Psychiatric and suicide & 32 & $40 \cdot 7$ & 434 & $432 \cdot 4$ & 466 & $473 \cdot 0$ & 99 \\
\hline Malignant & 400 & $468 \cdot 5$ & 110 & $95 \cdot 0$ & 510 & $563 \cdot 4$ & $91^{*}$ \\
\hline Nervous system and senses & 9 & $96 \cdot 6$ & 157 & $182 \cdot 8$ & 166 & $279 \cdot 4$ & $59 \ddagger$ \\
\hline Genitourinary & 7 & $26 \cdot 7$ & 16 & $18 \cdot 2$ & 23 & $44 \cdot 9$ & $51 \div$ \\
\hline Gastrointestinal & 29 & $55 \cdot 7$ & 77 & $157 \cdot 1$ & 106 & 212.9 & $50 \div$ \\
\hline Respiratory & 39 & $100 \cdot 5$ & 257 & $589 \cdot 8$ & 296 & $690 \cdot 3$ & $43 \ddagger$ \\
\hline Tuberculosis & 0 & $13 \cdot 8$ & 2 & $72 \cdot 6$ & 2 & $86 \cdot 5$ & $2 \ddagger$ \\
\hline Other causes & 44 & $35 \cdot 7$ & 257 & $299 \cdot 8$ & 301 & $333 \cdot 5$ & 90 \\
\hline All causes & 1322 & $1426 \cdot 4$ & 2722 & $2767 \cdot 5$ & 4044 & 4193.9 & $96^{*}$ \\
\hline
\end{tabular}

Observed population 419930 man-years.

${ }^{*} \mathrm{p}<0.05 ; \quad$ tp $<0.01 ; \quad \neq \mathrm{p}<0.005$

Table 4 Twenty-year changes in causes of medical wastage in women aged 25-59. (Women dying or medically retired in 1978-80 compared with expected number had age-specific rates for 1953-62 applied to 1978-80 populations)

\begin{tabular}{|c|c|c|c|c|c|c|c|}
\hline \multirow{2}{*}{$\overline{\text { Diagnostic group }}$} & \multicolumn{2}{|c|}{ Deaths } & \multicolumn{2}{|c|}{ Medical retirement } & \multicolumn{2}{|c|}{ Wastage } & \multirow[t]{2}{*}{ Standard wastage ratio } \\
\hline & Obs & Exp & Obs & Exp & Obs & Exp & \\
\hline Musculoskeletal & 1 & 0 & 138 & $57 \cdot 8$ & 139 & $57 \cdot 8$ & $240_{+}^{+}$ \\
\hline Injuries & 7 & $8 \cdot 7$ & 16 & $5 \cdot 4$ & 23 & $14 \cdot 1$ & $163^{*}$ \\
\hline Coronary heart disease & 22 & $17 \cdot 8$ & 34 & $19 \cdot 5$ & 56 & $37 \cdot 3$ & $150+$ \\
\hline Respiratory & 7 & $11 \cdot 2$ & 37 & $27 \cdot 7$ & 44 & 38.9 & 113 \\
\hline Malignant & 91 & $89 \cdot 0$ & 46 & $37 \cdot 7$ & 137 & $126 \cdot 6$ & 108 \\
\hline Other cardiovascular & 21 & $105 \cdot 3$ & 89 & $12 \cdot 0$ & 110 & $117 \cdot 3$ & 94 \\
\hline Psychiatric and suicide & 3 & $9 \cdot 0$ & 186 & $202 \cdot 5$ & 189 & $211 \cdot 4$ & 89 \\
\hline Gastrointestinal & 2 & $5 \cdot 3$ & 20 & $20 \cdot 1$ & 22 & $25 \cdot 4$ & 87 \\
\hline Nervous system and senses & 1 & $24 \cdot 7$ & 54 & $71 \cdot 1$ & 55 & $95 \cdot 8$ & $57 \ddagger$ \\
\hline Genitourinary & 0 & $6 \cdot 5$ & 10 & $11 \cdot 4$ & 10 & $17 \cdot 8$ & 56 \\
\hline Tuberculosis & 0 & $0 \cdot 2$ & 0 & $7 \cdot 1$ & 0 & $7 \cdot 3$ & $0 \dagger$ \\
\hline Other causes & 3 & $5 \cdot 8$ & 58 & $89 \cdot 7$ & 61 & $95 \cdot 5$ & $64 \dagger$ \\
\hline All causes & 159 & $189 \cdot 1$ & 689 & $658 \cdot 7$ & 848 & $847 \cdot 7$ & 100 \\
\hline
\end{tabular}

Observed population 88431 woman-years.

${ }^{*} \mathrm{p}<0.05 ; \quad+\mathrm{p}<0.01 ; \quad \ddagger \mathrm{p}<0.005$. 
most of which was caused by chronic bronchitis, was significantly reduced in men but rose slightly in women. While psychological disorders became more important as causes of sickness absence (table 3), there was no significant change in their contribution to medical wastage. Probably the increase in absence may have been due to a greater preparedness on the part of doctors and patients to include such diagnoses on certificates than had been the case hitherto.

There were some interesting differences in the change in diagnostic pattern within the nine main job groups. Postmen, for example, showed a significant overall reduction in wastage rate over this period (observed 1924, expected $2052.6 \mathrm{p}<0.01$ ), and they were the only male grade to show significantly lower rates from psychological conditions (observed 174, expected 236.1 p $<0.0005$ ). Their experience in terms of other diagnoses was similar to those of all men. Male telephonists, on the other hand, showed no significant rise in musculoskeletal but a substantial increase in psychological conditions (observed 50, expected $34.6 \mathrm{p} \bumpeq 0.01$ ). The male group showing the greatest increase in psychological conditions was that of postal clerks, for whom 38 cases were observed and 7.2 expected, a five-fold increase significant at the $0.05 \%$ level. On the other hand, the three female grade groups, which included telephonists, postal, and telecommunications clerical staff, were more consistent in their changes in rate. In these diagnostic groups calculations of Chi-square have subtracted Yates's correction for continuity.

\section{Comment}

The results of our analysis of the 90-year period of Post Office statistics on health and disease may best be summed up by the phrase plus ça change, plus c'est la même chose. The stability of death rates and the three relatively stable periods of sickness absence separated by two world wars, both of which seemed to set absence running at a substantially higher level, and the pronounced change in diagnostic pattern even when overall rates had changed little, all combine to support this phrase. The stability of sickness absence rates since 1953 is the more surprising in view of the well-recognised rise both in National Insurance sickness benefit rates ${ }^{14}$ and the comprehensive analysis from London Transport for the two decades of the 1950s and 1960s. ${ }^{15}$ Similar experiences have been noted by organisations throughout industry and commerce even though relatively few have been publicly documented. The Post Office's ability to hold its sickness absence rate at a reasonably steady level provides considerable justification for its comprehensive procedures (agreed by the unions) to control absence. This is a managerial programme, and the role of occupational physicians and nurses and of the welfare officers is strictly advisory, both to management as well as to individuals.

The observation that the correlation between medical retirement rates and sickness absence rates changed from negative to positive over the past 25 years is also worthy of note since it took place with no change in official Post Office policy. The strongly positive relationship supports, over a longer time scale, the observations recorded a few years ago when medical wastage rates were found to correlate positively with certified sickness absence both within job groups and within regional boundaries for the years 1972-5.11

We hope that further analyses of this long-time series with other health, social, and economic indices may cast further light on possible reasons for the fluctuations described in this paper.

\section{References}

${ }^{1}$ Post Office Archives. The Post Office medical system 1855-1902. (Collected papers 1902. Cat 64, vol 1.)

2 Bashford HH. Post Office Medical Service. London: HMSO, 1936. (Post Office Green Papers No 31.)

${ }^{3}$ Roberts CG. Post Office medical services and morbidity statistics. Monthly Bulletin of Ministry of Health 1948; 7:184-201.

4 Post Office Archives. Sick leave conditions. (Collected papers 1902. Cat 64, vol 4.)

${ }^{5}$ Manpower Services Commission. The quota scheme for the employment of disabled people. A discussion document. London: MSC Employment Division, 1979.

${ }^{6}$ Taylor PJ. A combined survey of chronic disability in industrial employees. Transactions of the Society of Occupational Medicine 1970;20:98-102.

${ }^{7}$ Government Actuary. Report on sick absences. Post Office. London: HMSO, 1937.

${ }^{8}$ Documenta Geigy Scientific Tables. 7th ed. Basle, Switzerland: Geigy SA, 1970:168.

${ }^{9}$ Bashford $\mathrm{HH}$. Some aspects of sickness absence in industry. Br J Ind Med 1944;1:7-10.

${ }^{10}$ Roberts CG, Reid DD. Premature disablement and death among Post Office workers. Br J Prev Soc Med 1954;8: 147-52.

11 Taylor PJ. Occupational and regional associations of death, disablement, and sickness absence among Post Office staff 1972-5. Br J Ind Med 1976;33:230-5.

12 Taylor PJ. Stress in relation to premature medical retirement. J Soc Occup Med 1979;29:95-101.

13 Taylor PJ. Tuberculosis in the Post Office 1973-6. Public Health Laboratory Service. Communicable Diseases Report 25. London: PHLS, 1977.

${ }^{14}$ Whitehead FE. Trends in certificated sickness absence. Social Trends 1971 No 2, 13-23.

15 Ager JE, Raffle PAB. Patterns in sickness absence. London: London Transport Executive, 1973. 